\title{
Low-salinity flooding in a selected carbonate reservoir: experimental approach
}

\author{
Hazim H. Al-Attar • Mohamed Y. Mahmoud • \\ Abdulrazag Y. Zekri • Reyadh Almehaideb • \\ Mamdouh Ghannam
}

Received: 29 October 2012/Accepted: 3 March 2013/Published online: 17 March 2013

(C) The Author(s) 2013. This article is published with open access at Springerlink.com

\begin{abstract}
Low-salinity waterflooding has been used to improve oil recovery for many decades. Several theories regarding the mechanism of low-salinity flooding have been discussed in the literature including interfacial tension reduction, wettability alteration, change in $\mathrm{pH}$ value, emulsion formation, and clay migration. This work presents the results of flooding tests on selected carbonate core samples taken from Bu Hasa field in Abu Dhabi using sea water and two field injection waters, Um-Eradhuma (UER) at $197,357 \mathrm{ppm}$ and Simsima at $243,155 \mathrm{ppm}$. These results were used to evaluate the effects of brine salinity and ionic composition on the possible interactions of limestone rock/ brine/and oil system and to identify the oil recovery mechanism. The field injection waters were diluted to salinities of 5,000 and 1,000 ppm and the optimum salinity was determined and then modified by varying the sulfate and calcium ion concentrations. Wettability alteration was determined by contact angle measurements. Interfacial tension measurements of the studied systems were also performed in an attempt to evaluate the flow mechanism with low-salinity flooding. The experimental results revealed that a significant improvement in the oil recovery can be achieved through alteration of the injection water salinity. Reducing the salinity of UER water from 197,357 to 5,000 ppm resulted in an improvement of oil recovery from 63 to $84.5 \%$ of OOIP and the latter salinity was used to evaluate the impact of changing the sulfate and calcium ion concentrations on oil recovery. Results also indicated that sulfate
\end{abstract}

H. H. Al-Attar $(\varangle) \cdot$ M. Y. Mahmoud .

A. Y. Zekri · R. Almehaideb · M. Ghannam

Chemical and Petroleum Engineering Department,

United Arab Emirates University,

Al Ain, United Arab Emirates

e-mail: hazim.alattar@uaeu.ac.ae concentration has a significant effect on the flooding process and that increasing the sulfate concentration beyond some optimum concentration of $46.8 \mathrm{ppm}$ resulted in a negative effect on the flooding process. Contact angle measurements indicated that lowering the solution salinity could shift the wettability of the system towards intermediate wettability levels and that the UER water exhibits higher shift toward intermediate wettability compared to other waters. Results also indicated that there is no clear correlation between the improvements in oil recovery and interfacial tension and the $\mathrm{pH}$ of the studied systems. The results of this work are useful for people working in this field.

Keywords Low-salinity flooding - IFT · EOR · Wettability · Oil recovery

\section{Introduction}

Low-salinity waterflooding was first attempted by researchers at The University of Wyoming during the 90s by examining the effect of brine, crude oil, mineralogy and experimental procedure on rock surface-wettability. In the subsequent decade, the technology of low-salinity flooding was repeatedly implemented in the laboratory and in the field. Over the past decade low-salinity waterflooding has emerged as a viable enhanced oil recovery (EOR) method. Both laboratory tests and field trials have shown that injecting chemically modified water instead of seawater can lead to incremental oil recoveries. Although much research has been conducted, the governing physical and chemical mechanisms for this increase in recovery are not yet agreed upon, but are generally believed to involve some form of interaction between the rock, oil, and brine leading to changes in wettability, oil/water interfacial tension, or both.

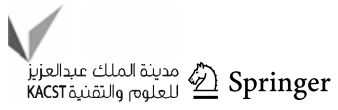


Yildiz and Morrow (1996) conducted core floods using Berea sandstone, Moutray crude oil and either sodiumbased brine composed of $4 \% \mathrm{NaCl}+0.5 \% \mathrm{CaCl}_{2}$ or calcium-based brine composed of $2 \% \mathrm{CaCl}_{2}$. Recovery was higher with the calcium brine when the connate and injected brines were identical. The highest recovery was achieved by initially saturating the core with calcium brine, injecting $\mathrm{Na}$ brine until residual oil saturation was achieved, then injecting calcium brine. Tang and Morrow (1997) investigated the effects of connate and injection brine salinity, aging time and temperature on water flooding and imbibition with 3 different crude oils and 3 different brines. They concluded that in water floods with constant connate brine salinity and variable injected brine salinity, diluting injected brine 100 times produced $\sim 5 \%$ incremental oil recovery. In water floods with variable connate brine salinity and constant injected brine salinity, decreasing connate brine salinity dramatically improved recovery-about $40 \%$ incremental oil recovery was achieved by diluted the connate brine 100 times.

Based on the above findings, researchers began to focus on the only variable that can be manipulated in a reservoir-the injection brine salinity. Researchers noticed that improved recovery by injection of low-salinity brine only occurred when crude oil and clay bearing sandstone mineralogy were present. Based on this observation, Tang and Morrow (1999a, b) offered the first theoretical interpretation of the mechanism responsible for the recovery improvement. They observed an increase in water flood and spontaneous imbibition recovery with a decrease in salinity in numerous cases. The authors used Berea cores, CS crude, and refined oil and 7 different brines ranging from $35,960 \mathrm{ppm}$ TDS down to $151.5 \mathrm{ppm}$ TDS. Oil Recovery improved significantly in the CS reservoir and Berea cores when low-salinity brine was injected instead of high salinity, but recovery improved only marginally in the more clay-free cores. Berea cores that were fired and acidized, to stabilize fines, were insensitive to brine salinity. Tang and Morrow (1999a, b) concluded that heavy polar components in the crude oil adsorb onto fine particles along the pore walls and that these mixed-wet fines are stripped by low-salinity brine, altering wettability and increase oil recovery.

Zhang and Morrow (2006) conducted water flood and spontaneous imbibition experiments using 4 different samples of Berea sandstone and three different crude oils. These authors observed improved recovery by injecting low-salinity brine in secondary and tertiary modes. The impact of low-salinity brine varied significantly between the different samples of Berea, suggesting that mineralogy was the most important variable affecting improved recovery. The lowest permeability block of Berea $\left(k_{\text {nitrogen }}\right.$ $\sim 60-140 \mathrm{md}$ ) showed no sensitivity to salinity. The lack of response was attributed to the presence of chlorite. In several cases, cores responded to low-salinity brine in the secondary but not the tertiary mode. Low-salinity effects become more dramatic as the initial water saturation increased. In all cases, injection of low-salinity brine was accompanied by an increase of pressure followed by a gradual decrease. Effluent $\mathrm{pH}$ also increased.

Some publications indicated that there is no benefit of low-salinity waterflooding. Sharma and Filoco (2005) investigated the impact of connate and injection brine salinity and crude oil on oil recovery, residual saturations and wettability using Berea cores, 3 different oils and $\mathrm{NaCl}$ brine in various concentrations. In their imbibition experiments, decreasing connate water salinity increased recovery and significantly affected relative permeability. The salinity of the displacing brine had no significant impact. Drainage experiment's recovery and relative permeability were insensitive to salinity. During waterflooding of crude oil, oil recovery increased with decreasing connate brine salinity. However, during waterflooding of mineral oil, recovery was insensitive to connate brine salinity. In all cases, waterflood recovery was insensitive to the salinity of the injected brine. Sharma and Filoco suggested that lowsalinity connate brine changes the wetting properties of the rock surface from water-wet to mixed-wet and thereby increase the recovery.

Webb et al. (2003) observed a reduction in residual oil saturation in the near wellbore region by injecting lowsalinity brine. Three different brines were injected into a clastic formation from a producing well. Saturation was measured after each injection using a pulsed neutron capture log. A base line $S_{\text {or }}$ was established with a synthetic native brine $(250,000 \mathrm{ppm})$. Synthetic sea water (120,000 ppm), injected second, did not reduce oil saturation further. Low-salinity brine (3,000 ppm), injected last, reduced $S_{\text {or }}$ significantly in two sand intervals and slightly in another.

Zhang et al. (2007) reported increased recovery in the tertiary mode by reducing reservoir brine salinity 20 times. Two consolidated reservoir sandstone cores were used. $\mathrm{X}$-ray diffraction indicated that each of the cores were rich in chert and kaolinite. Two different crudes and a mineral oil were used. Almost $70 \%$ incremental oil recovery was achieved in the secondary mode. Both the high and lowsalinity secondary floods were conducted in the same core. Tertiary recovery was also quite large; $25 \%$ incremental recovery in the best case. The recovery was achieved slowly, taking more than 10 injected pore volumes. In several cases, the $\mathrm{pH}$ fell upon injection of low-salinity brine; contrary to other researcher's observations. Pressure drop was closely tied to incremental recovery. In all cases, where significant incremental recovery was achieved pressure drop increased significantly then fell gradually. 
Pu et al. (2008) observed low-salinity tertiary recovery from an almost clay-free core for the first time. They injected coalbed methane (CBM) water into 3 sandstone reservoir cores composed of quartz, feldspar, dolomite, and anhydrite cements but which had very little clay. The CBM water's salinity was about $1,316 \mathrm{ppm}$ TDS. Cores were first waterflooded with high salinity formation brine $(38,651 \mathrm{ppm})$. When oil production due to high salinity brine ceased CBM water was injected. In all cases CBM water liberated additional oil. In each core, the benefit of tertiary low-salinity flooding became less dramatic after each flood and restoration. A core was acidized to remove dolomite crystals and subsequently its recovery became insensitive to low-salinity flooding. Pu et al. proposed that dolomite crystals play an important role in the low-salinity recovery mechanism. Some of the dolomite crystals become mixed-wet as they contacted the oil phase during aging. During the low-salinity flood the dolomite crystals may detach from the pore walls releasing oil from the rock surface. The detached dolomite crystals will then reside at the crude oil/brine interface increasing resistance to flow of brine at the interface, delay snap-off at pore-throats and preventing the collapse of oil lamella.

Bagci et al. (2001) studied the effect of brine composition on oil recovery by water flooding using limestone cores. Ten different brine compositions were examined for injection through the study. The brines were $\mathrm{NaCl}$, $\mathrm{CaCl}_{2}, \mathrm{KCl}$, and binary mixtures of them at two different concentrations ( 2 and $5 \mathrm{wt} \%$ ). The highest oil recovery was $35.5 \%$ of original oil in place (OOIP) for $2 \mathrm{wt} \%$ $\mathrm{KCl}$. The authors concluded that any adjustment to the injected brine composition of a mature waterflood can offer a possible and economically feasible approach to increase oil production. Wettability alteration was mentioned as a reason for recovering more oil but without any further explanation. These authors used long core samples (20 inches) in the folding experiments and at a reservoir temperature of $122^{\circ} \mathrm{F}$. Low-salinity effluent brine samples showed higher $\mathrm{pH}$ and that was caused by ions exchange reaction.

Høgnesen et al. (2005) concluded that any modification to the injection water ions can impact rock wettability and that can result in additional oil to be recovered. They presented an imbibition study at high temperature condition using reservoir limestone, outcrop chalk cores, seawater and formation water. The results showed that increasing the sulfate ion concentration at high temperature can act as a wettability modifying agent in carbonates, and increased the oil recovery. Scale and souring problems will be enhanced as increasing the sulfate concentration in the injected water. Moreover, this strategy has limitations with regard to initial brine salinity and temperature. At low temperature condition, cationic surfactant was mixed with the aqueous solution and that increased the spontaneous imbibition through the cores.

Webb et al. (2005) presented a study that compared oil recovery from a North Sea carbonate core samples using sulfate-free formation simulated brine, with seawater, which contains sulfate. The imbibition capillary pressure experiments were performed at reservoir conditions using live crude oil and brine. The final results showed that the simulated seawater was able to modify the wettability of the carbonate system, changing the wettability of the rock to a more water-wet state. This conclusion was based on the saturation change noted in the spontaneous imbibition tests between simulated formation water and sea water.

Most of the low-salinity waterflood studies were conducted on limestone; seawater, also, was recommended as an injection fluid in chalk formations. Strand and Austad (2008) explained in preliminary experimental studies the chemical mechanism for the wettability alteration in fractured limestone after injecting seawater, sodium chloride brine, and formation water.

Synthetic seawater with and without sulfate ions was used to determine the sulfate ions effect on wettability. Spontaneous imbibition results at $248^{\circ} \mathrm{F}$ showed $15 \%$ increase in the oil recovery when limestone core was imbibed with seawater compared to seawater free of sulfate ions. Seawater has the lowest TDS compared to the other examined brines, but it did not include any brine test that has lower salinity than seawater. More details on reaction mechanism will be explained in the next section. Fjelde (2008) presented results on low-salinity water that increased oil recovery in limestone formation. Spontaneous imbibition experiments were conducted using formation water and low-salinity water. Low-salinity water showed similar oil recovery results to seawater experiments. No further details were mentioned in this work. Paul Vledder et al. (2010) work showed that the wettability can be changed at a reservoir scale, similar to more controlled experiments such as laboratory experiments and LogInject-Log tests. A large number of observations consistently prove this change in wettability that is shown to lead to an increased recovery factor. The incremental recovery due to the change in wettability on a field wide scale is 5-15\%. This range mostly overlaps with the range obtained from the experimental data (9-23\%) and therefore the final conclusion is that the incremental recovery due to low-salinity injection in Omar Field amounts to $10-15 \%$ of the STOIIP. The main issues to be managed are water sourcing, water disposal and water mixing in the reservoir.

The objective of this work is to investigate the merits of using low-salinity flooding techniques to enhance oil recovery in Bu Hasa reservoir, identify the mechanism involved in the additional recovery of oil by low-salinity 
flooding, and evaluate the effect of different ions $\left(\mathrm{SO}_{4}{ }^{2-}\right.$ and $\mathrm{Ca}^{2+}$ ) on the overall recovery process.

\section{Experimental materials and setup}

\section{Materials}

Reservoir crude oil from $\mathrm{Bu}$ Hasa field was used in all experiments. The oil was filtered through a 5.0- $\mu \mathrm{m}$ filter paper (with a vacuum pump) to remove any possible solid particles. The oil is sweet oil and has no $\mathrm{H}_{2} \mathrm{~S}$ and about 2.6 mole\% $\mathrm{CO}_{2}$ which is very low. The oil density and viscosity are $0.825 \mathrm{~g} / \mathrm{cc}$ and $3.08 \mathrm{cp}$ measured at room temperature of $25^{\circ} \mathrm{C}$, respectively. Four types of water were used. The first type was Um-Eradhuma (UER) water which is the injection water that has been used in flooding the reservoir for many years. A live sample of this water was filtered, degassed, and then used in the experiments. This water has a salinity of $197,357 \mathrm{ppm}$ and density of $1.15 \mathrm{~g} / \mathrm{cc}$. The second type was Simsima (SIM) water which is formation water that has been used in water flooding the reservoir for many years. A live sample of this water was filtered, degassed, and then used in the experiments. Its salinity is $243,155 \mathrm{ppm}$ and its density is $1.16 \mathrm{~g} / \mathrm{cc}$. The third type is sea water (SW) which was collected from one of the Arabian Gulf beaches in Abu Dhabi. It was filtered, degassed, and then used in the experiments. Its salinity is about $40,980 \mathrm{ppm}$ and its density is $1.029 \mathrm{~g} / \mathrm{cc}$. The fourth type was lab-prepared distilled water. Table 1 shows the analysis of these water samples.

Five core samples were selected from well number 589 in Bu Hasa field. The physical properties of these cores are listed in Table 2. Four of these core samples were used in the flooding experiments, namely, numbers $31,39,40$, and 42. The fifth core sample (no. 46) was used for contact angle measurements. The mineral composition of these core samples and others are listed in Table 3.

\section{Experimental setup}

Oil floods were conducted at constant injection pressure of $689.476 \mathrm{kPa}$ (100 psi) with overburden pressure of $5,515.808 \mathrm{kPa}(800 \mathrm{psi})$ and at room temperature of $25^{\circ} \mathrm{C}\left(77^{\circ} \mathrm{F}\right)$. The cores were positioned in a vertical configuration and oil was injected at the top as illustrated in Fig. 1. Effluent rate was regularly measured with a stop watch and pressure drop was monitored continuously. The core holder was designed for high pressure flood tests and to accommodate core samples of $3.86 \mathrm{~cm}$ (1.52 in.) in diameter and a maximum of $7.62 \mathrm{~cm}$ (3 in.) in length.

The core samples were first saturated with formation water and displaced by crude oil to $S_{\mathrm{wc}}$ using the standard Core Lab procedures. The analysis of this water is presented in Table 4. The crude oil-saturated cores were then aged in crude oil for 4 weeks and then flooded with various brines. The volumes of produced brine and oil were recorded as a function of time at constant pressure drop. To avoid fingering of the displacing phase, these flooding processes were conducted at low rate between 1 and $3 \mathrm{cc} / \mathrm{min}$. The injection of brine continued until oil ceased to show any production at the core outlet. The measured stable pressure $\operatorname{drop}(\mathrm{s})$ and the corresponding flow rate(s) were used to calculate end-point water permeability to water $\left(k_{\mathrm{rw}}\right)_{\text {Sor }}$ using Darcy's law. For example, the values of $\left(k_{\mathrm{rw}}\right)_{\text {Sor }}$ when flooding oil with 5,000 ppm UER water and $171,585 \mathrm{ppm}$ UER water are 0.17 and 0.29 , respectively. This observation is indicative of the system's wettability shift toward more water-wet as the end-point relative permeability to water decreases with decreasing of UER water salinity.

The material balance was then applied to calculate the residual oil saturation $\left(S_{\text {or }}\right)$. Figure 2 illustrates a block diagram of all test runs performed in this work. Experiments were conducted with UER water, SIM water, SW and distilled water. Experiments were then conducted using the dilutions of each type of water to determine the optimum water salinity. The effect of ionic concentration of sulfate and calcium ions on the flooding process was investigated using the optimum water salinity.

\section{Results and discussion}

\section{Flooding with UER water}

In order to evaluate the effect of different salinities on the recovery eleven core flooding tests were conducted. The UER brine was diluted to one-half of its original salinity, i.e., down to $98,679 \mathrm{ppm}$ then to $5,000 \mathrm{ppm}$ and finally to
Table 1 Analysis of the different types of water

\begin{tabular}{lrrrrrrrrr}
\hline Type & \multicolumn{1}{l}{$\mathrm{mg} / \mathrm{L}$} & \multicolumn{1}{c}{$\mathrm{Mg}^{++}$} & $\mathrm{Na}^{+}$ & $\mathrm{CO}_{3}$ & $\mathrm{HCO}_{3}{ }^{-}$ & $\mathrm{Cl}^{-}$ & $\mathrm{SO}_{4}^{-}$ & \\
\cline { 2 - 8 } & $\mathrm{Ca}^{++}$ & $\mathrm{K}$ & $\mathrm{Mg}^{-}$ & \\
\hline SIM & 20,808 & - & 3,047 & 68,214 & - & 119 & 150,617 & 350 & 243,155 \\
UER & 14,033 & - & 3,024 & 57,613 & - & 244 & 122,023 & 420 & 197,357 \\
SW & 600 & - & 1,560 & 13,900 & & 200 & 24,300 & 420 & 40,980 \\
\hline
\end{tabular}


Table 2 Properties of the selected core samples

\begin{tabular}{lllllllll}
\hline Sample no. & Depth $(\mathrm{m})$ & $L(\mathrm{~cm})$ & $D(\mathrm{~cm})$ & $k w(\mathrm{md})$ & Dry weight $(\mathrm{g})$ & Saturated weight $(\mathrm{g})$ & Pore volume $(\mathrm{cc})$ & $\phi$ Fraction \\
\hline 31 & 2650.206 & 7.090 & 3.843 & 8.7 & 164.080 & 186.700 & 20.423 & 0.248 \\
39 & 2650.267 & 7.032 & 3.850 & 8.5 & 163.470 & 184.960 & 19.402 & 0.237 \\
40 & 2650.937 & 7.247 & 3.853 & 8.7 & 170.210 & 192.370 & 20.007 & 0.237 \\
42 & 2652.309 & 7.272 & 3.855 & 8.8 & 190.160 & 205.030 & 13.425 & 0.158 \\
46 & 2652.400 & 7.160 & 3.860 & 7.7 & 190.800 & 204.130 & 0.144 \\
\hline
\end{tabular}

Table 3 X-ray diffractograms mineral composition of core samples

\begin{tabular}{lll}
\hline Sample no. & Major mineral & Minor mineral \\
\hline 31 & Calcite $\left(\mathrm{CaCO}_{3}\right)$ & Dolomite $\left[\mathrm{CaMg}\left(\mathrm{CO}_{3}\right)_{2}\right]$ \\
39 & Calcite $\left(\mathrm{CaCO}_{3}\right)$ & Dolomite $\left[\mathrm{CaMg}\left(\mathrm{CO}_{3}\right)_{2}\right]$ \\
40 & Calcite $\left(\mathrm{CaCO}_{3}\right)$ & Dolomite $\left[\mathrm{CaMg}\left(\mathrm{CO}_{3}\right)_{2}\right]$ \\
42 & Calcite $\left(\mathrm{CaCO}_{3}\right)$ & Dolomite $\left[\mathrm{CaMg}\left(\mathrm{CO}_{3}\right)_{2}\right]$ \\
46 & Calcite $\left(\mathrm{CaCO}_{3}\right)$ & Dolomite $\left[\mathrm{CaMg}\left(\mathrm{CO}_{3}\right)_{2}\right]$ \\
\hline
\end{tabular}

$1,000 \mathrm{ppm}$. The flooding results of this set of experiments are plotted as oil recovery percent of OOIP versus pore volumes injected of brine as shown in Fig. 3.

Figure 3 shows that the highest oil recovery was obtained from the $5,000 \mathrm{ppm}$ dilution which is about $84.5 \%$ of the OOIP. The lowest oil recovery percent observed when using the distilled waters was about $60.5 \%$ of the OOIP. The 1,000 ppm dilution yielded a lower oil recovery than the 5,000 ppm solution and all the diluted UER waters resulted in a higher oil recovery than the distilled water. Therefore, the salinity of 5,000 ppm was considered as the optimum salinity for further evaluation.

\section{Flooding with SIM water}

Simsima brine with its original salinity of $243,155 \mathrm{ppm}$ was first diluted by $50 \%$ (salinity of $121,578 \mathrm{ppm}$ ) then down to $5,000 \mathrm{ppm}$ and finally to $1,000 \mathrm{ppm}$. The results of this part are illustrated in Fig. 4.
Figure 4 shows that the highest oil recovery of $74.4 \%$ of the OOIP was obtained with the $1,000 \mathrm{ppm}$ dilution. The lowest oil recovery of $48.9 \%$ of the OOIP was observed with the original SIM water. The $50 \%$ dilution resulted in a recovery percent of $53.5 \%$ of the OOIP then the $5,000 \mathrm{ppm}$ dilution resulted in a recovery of $70.0 \%$ of the OOIP.

Flooding with sea water

Sea water brine of original salinity of $40,980 \mathrm{ppm}$ was diluted to $5,000 \mathrm{ppm}$. The results of this section are shown in Fig. 5.

Figure 5 shows that original SW resulted in a recovery of $60.2 \%$ of the OOIP and the 5,000 ppm brine showed a recovery of $62.2 \%$ of the OOIP and the distilled water resulted in a recovery of $60.5 \%$ of the OOIP. The three waters resulted in comparable results as there is no significant increase in oil recovery by dilution.

The results presented in Figs. 3, 4, and 5 show that flooding core samples with the three different brines at their original salinities resulted in the lowest ultimate oil recoveries. Also, by diluting these brines to lower salinities the oil recovery increased significantly except for SW as its original salinity is not high as in UER and SIM brines. The highest oil recovery of $84 \%$ of OOIP recovery was achieved by flooding with UER brine at 5,000 ppm. Tang and Morrow (1999a, b) observed similar trends and
Fig. 1 A schematic diagram of the core flooding setup

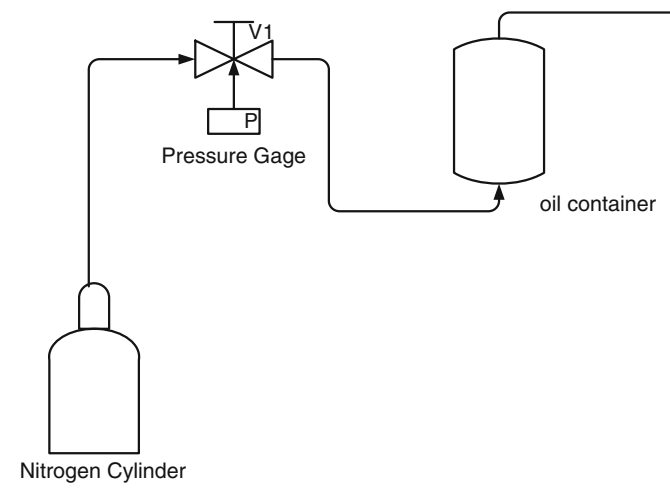

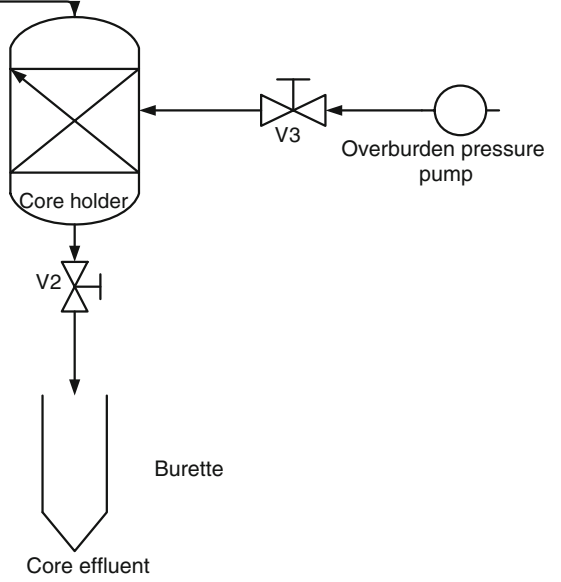

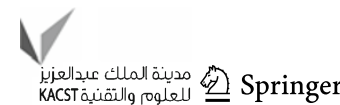


attributed these improvements to the presence of clay in their core samples. They concluded that the flow mechanism in low-salinity flooding is highly controlled by the clay. The core samples used in this work are clay-free and

Table 4 Analysis of formation water

\begin{tabular}{lr}
\hline Element & Concentration, $\mathrm{mg} / \mathrm{L}$ \\
\hline Sodium & 51,820 \\
Calcium & 15,992 \\
Magnesium & 1,282 \\
Iron & 277 \\
Barium & 0 \\
Chloride & 111,852 \\
Bicarbonate & 391 \\
Sulfate & 272 \\
Carbonate & 0 \\
Hydroxide & 0 \\
\hline
\end{tabular}

therefore another flow mechanism was responsible for the increased oil recovery by low-salinity flooding. Pu et al. (2008) observed increased oil recovery but in clay-free core samples. They proposed that dolomite crystals could play an important role in the low-salinity recovery mechanism.

Results of changing ionic composition of the brine

To evaluate the effect of $\mathrm{Ca}^{2+}$ and $\mathrm{SO}_{4}{ }^{2-}$ concentrations on the performance of low-salinity flooding, two sets of core flooding runs were conducted. The 5,000-ppm dilution of UER brine was used as the base water for evaluating the effect of ionic composition because the highest oil recovery of $84 \%$ of the OOIP was achieved by the 5,000-ppm dilution of UER brine. The first set of experiments involved flooding core samples with water UER at $5,000 \mathrm{ppm}$ and sulfate concentrations of $11.7,23.4,46.8$, and $70.2 \mathrm{ppm}$, respectively. Brine concentration was varied by changing

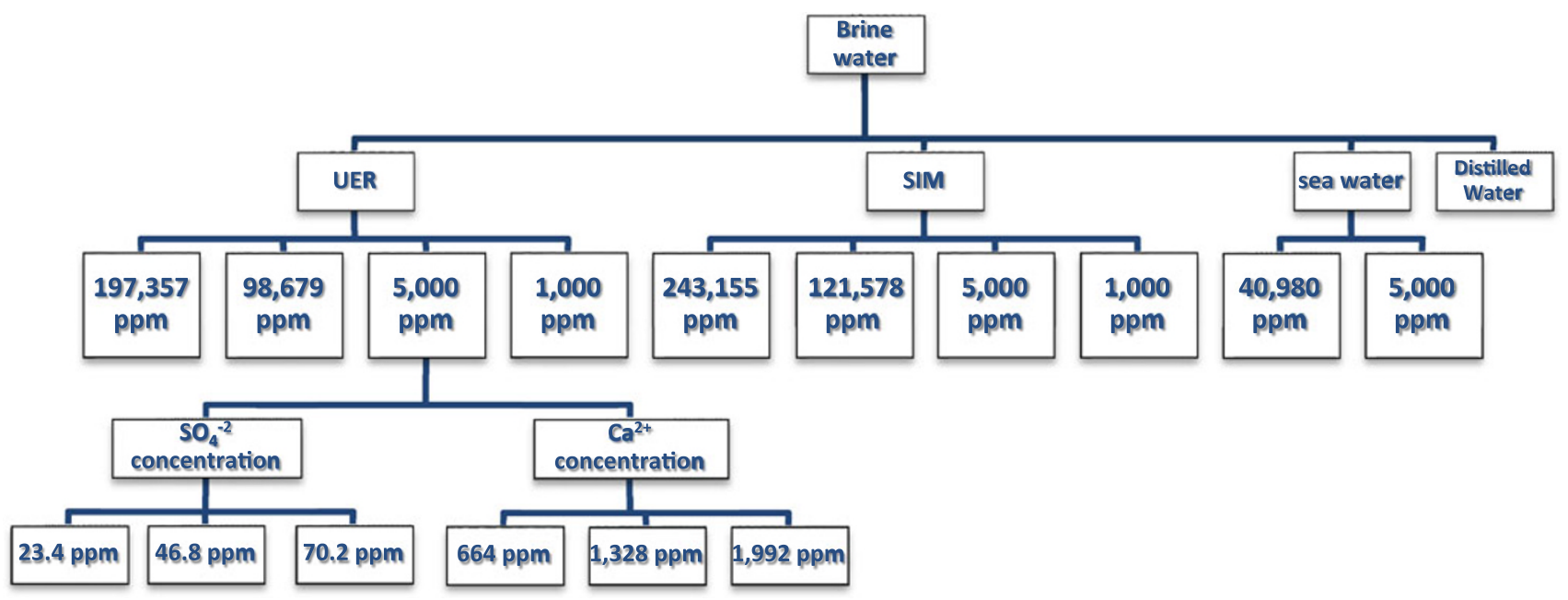

Fig. 2 Block diagram showing the various experimental runs performed in this work

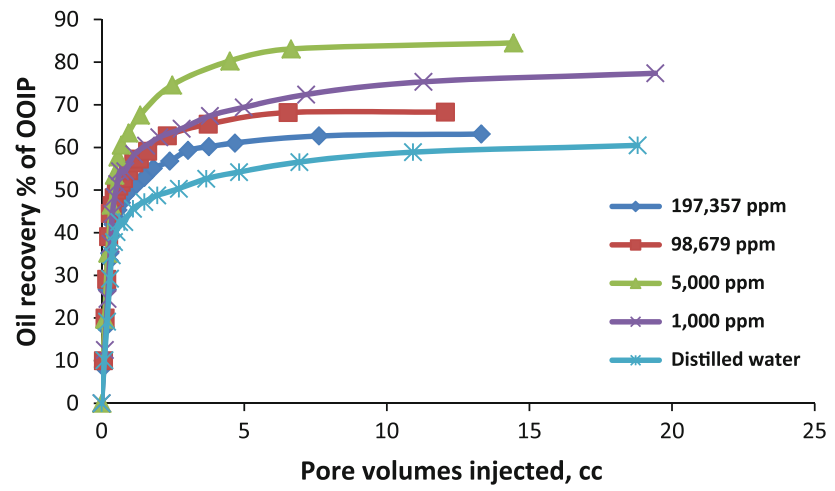

Fig. 3 Oil recovery \% of OOIP versus pore volumes injected of UER water with different salinity concentrations; figures between brackets represent percent of dilution of original salinity concentration

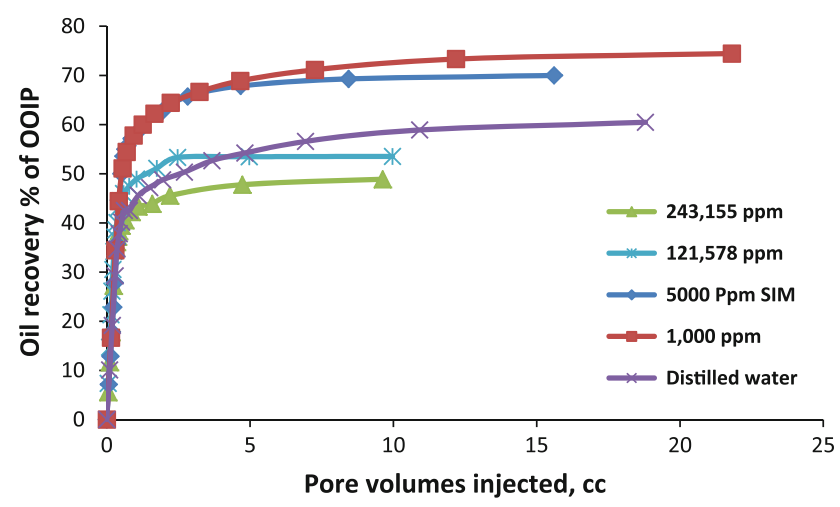

Fig. 4 Oil recovery \% of OOIP versus pore volumes injected of SIM water with different salinity concentrations; figures between brackets represent percent of dilution of original salinity concentration 


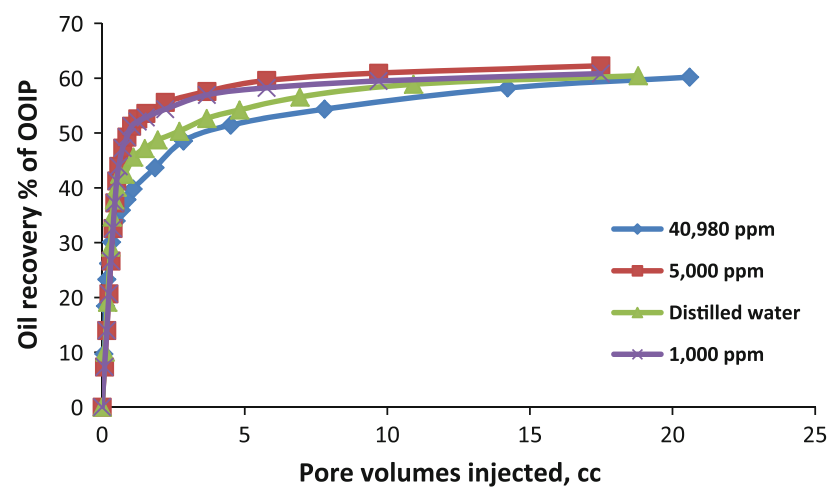

Fig. 5 Oil recovery $\%$ of OOIP versus pore volumes injected of SW water with different salinity concentrations; figure between brackets represent percent of dilution of original salinity concentration

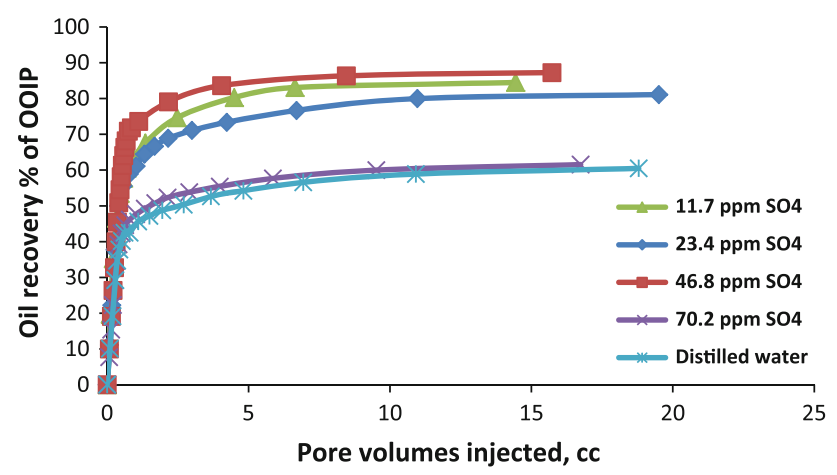

Fig. 6 Oil recovery versus pore volumes injected brine at different $\mathrm{SO}_{4}{ }^{2-}$ concentrations

the concentration of total dissolved solids of the synthetic brine in proportion to give sulfate content of $23.4,46.8$, and $70.2 \mathrm{ppm}$ by adding $\mathrm{Na}_{2} \mathrm{SO}_{4}$. The ionic strength of these solutions was kept constant by adjusting the content of $\mathrm{NaCl}$. The results of this set of experiments are shown in Fig. 6.

Figure 6 shows that with sulfate concentration of $46.8 \mathrm{ppm}$ (four times the original sulfate concentration in the UER water) the highest oil recovery of $87.2 \%$ of the OOIP was achieved. The sulfate concentration of $70.2 \mathrm{ppm}$ (six times the original sulfate concentration) resulted in the lowest oil recovery of $61.5 \%$ of the OOIP which is comparable to the distilled water of $60.5 \%$ of the OOIP. Figure 6 also shows that increasing the sulfate concentration in the brine solution could increase the oil recovery until a critical value of sulfate concentration is reached above which oil recovery decreased. Similar trends were observed by Webb et al. (2005). In their study, they compared oil recovery from a North Sea carbonate core samples using sulfate-free formation simulated brine with seawater, which contains sulfate. The final results showed that the simulated seawater was able to increase the recovery by 20 percent. There is no clear evidence on the critical sulfate concentration in the literature.

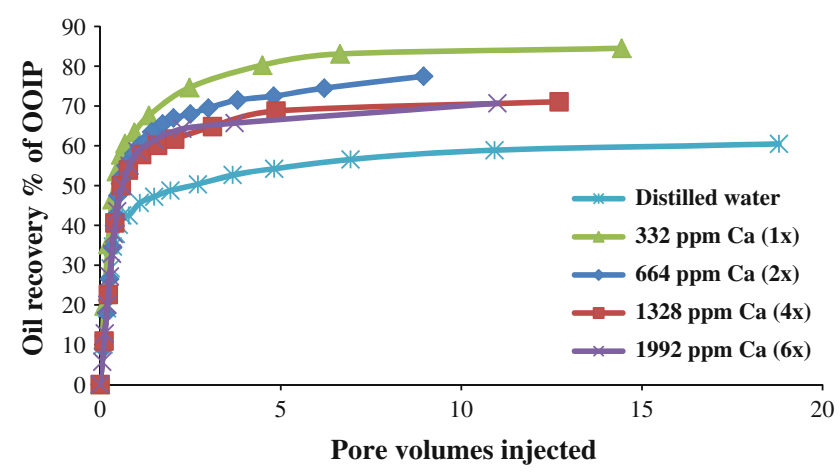

Fig. 7 Oil recovery versus pore volumes injected brine at different $\mathrm{Ca}^{2+}$ concentrations

The second set of experiments in this section involved flooding core samples with UER water at 5,000 ppm containing calcium concentrations of $332,664,1,328$, and $1,992 \mathrm{ppm}$, respectively. Brine concentration was varied by changing the concentration of total dissolved solids of the synthetic brine in proportion to give brine of 664 , 1,328 , and 1992 ppm of calcium content by adding $\mathrm{CaCl}_{2}$. The ionic strength of these solutions was kept constant by adjusting the content of $\mathrm{NaCl}$. The results of this set of runs are shown in Fig. 7.

Figure 7 shows that calcium concentration has a negative effect on oil recovery. Flooding with the original calcium concentration of $332 \mathrm{ppm}$ yielded the highest oil recovery and by increasing the calcium concentration the oil recovery decreased. The MIE (multicomponent ionic exchange) concept that was proposed by Lager et al. (2008) and the Double layer effect that was suggested by Ligthelm et al. (2009) indicates that calcium plays a key role in the oil recovery process in the presence of clay. In this work, however, it is shown that in clay-free core samples, flooding with calcium could have a negative effect on oil recovery.

\section{Contact angle measurements}

The results of the sessile drop method were analyzed with Sigma Scan Pro image analysis software to determine the change of contact angle measurements with time. The results of these measurements for the oil-UER brine-rock, oil-SIM brine-rock, and oil-SW-rock systems considered in this work are illustrated in Figs. 8, 9, and 10, respectively.

The repeatability of the contact angle measurements was evaluated by calculating the percent deviation of a certain reading from the preceding value. The maximum deviation observed was approximately $1.37 \%$ which could be partially attributed to machine error. The early time fluctuations were observed in all the experiments of contact angle measurements. These fluctuations are believed to be attributed to the continuous change in the shape of the oil 


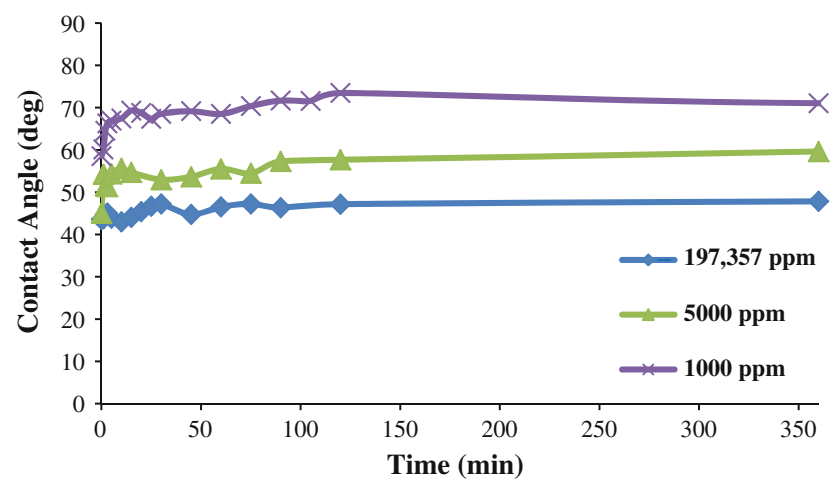

Fig. 8 Results of contact angle measurements for UER water and its corresponding diluted solutions

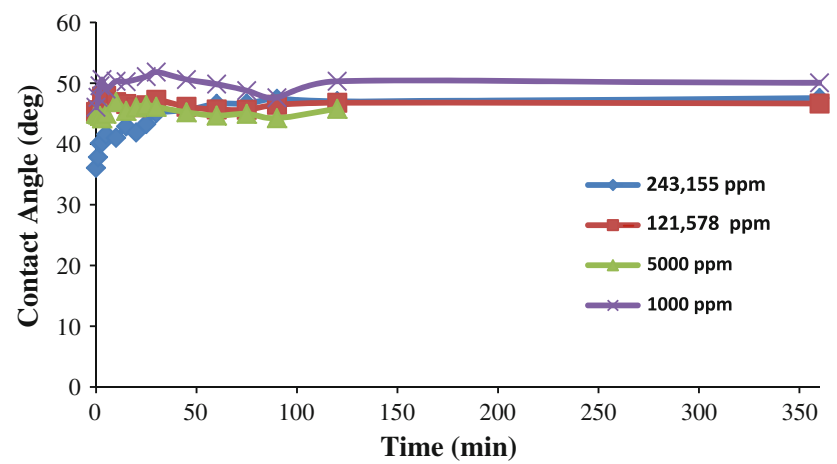

Fig. 9 Results of contact angle measurements for SIM water and its corresponding diluted solutions

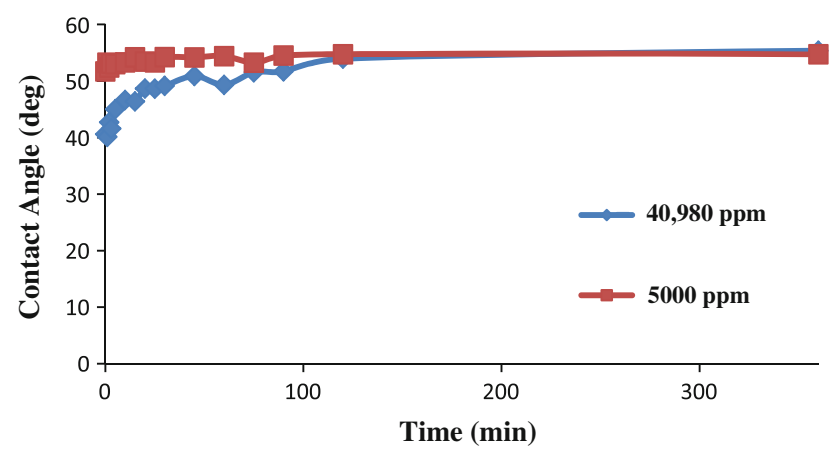

Fig. 10 Results of contact angle measurements for SW water and its corresponding diluted solutions

drop observed during the early time of the experiments. Once the shape of the oil drop reached a stabilized state, the fluctuations disappeared and a stable value of contact angle was observed for the rest of the experiment. Although not shown in Figs. 8, 9, 10, 11, and 12, each contact angle measurement was allowed to continue for 650 min to make sure that stabilization has been reached. Thus, it can be deduced that the fluctuations did consume some $20 \%$ of the testing time.

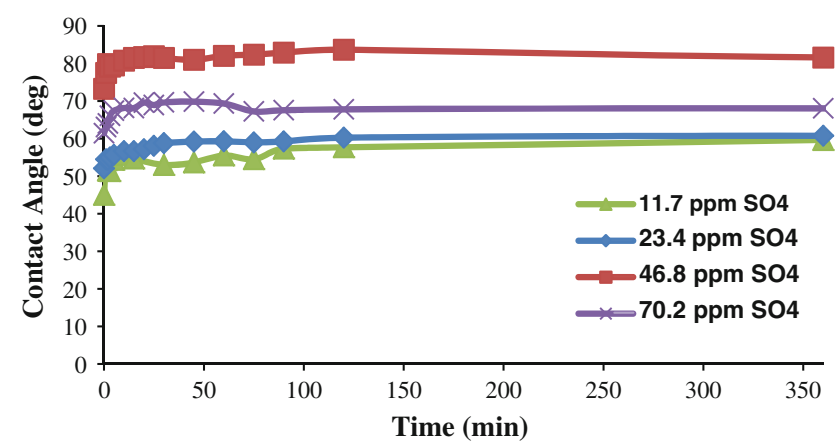

Fig. 11 Contact angle measurements for different $\mathrm{SO}_{4}{ }^{2-}$ concentrations

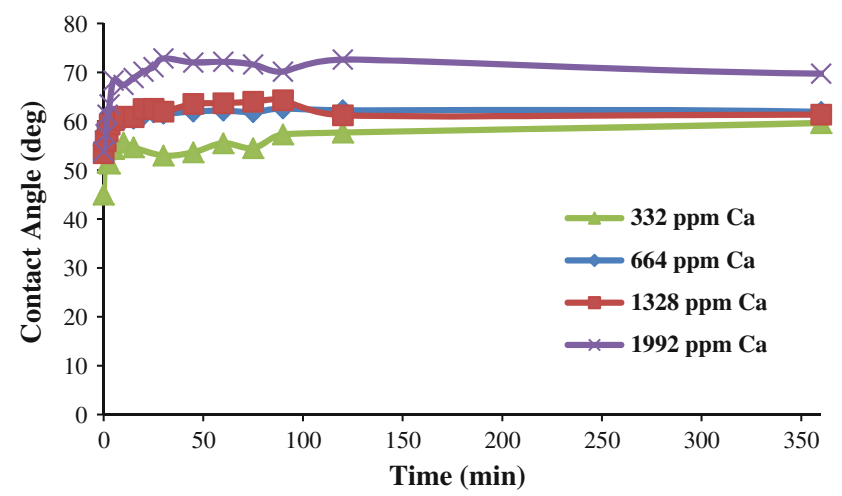

Fig. 12 Contact angle measurements for different $\mathrm{Ca}^{2+}$ concentrations

The results of contact angle measurements presented in Figs. 9 and 10 and the results of core flooding tests presented in Figs. 4 and 5 indicate that oil recovery could increase if the contact angle is increased. In other words, the oil recovery could increase as the wettability is changed to more intermediate levels. This observation is in contradiction with Jadhunandan and Morrow (1995), Tang and Morrow (1999a, b), Zhang and Morrow (2006); they all concluded that water-wet wettability yields higher oil recovery. Agbalaka et al. (2008) conducted a review on the effect of reservoir rock wettability on oil recovery for secondary and tertiary oil recovery processes. Several field cases as well as laboratory studies were discussed. The fact that wettability affects oil recovery can affect oil recovery efficiency is widely acknowledged. However, the wetting phase that will result in optimal recovery of oil has been the subject of intense debate. Agbalaka et al. (2008) observed that the reason for this divergence in observed reports is attributable to a number of factors which includes (1) difficulty in wetting state reproducibility, (2) lack of unified standards and procedure for coring, core handling and core storage, and (3) the wetting state characterization method adopted. They concluded that strongly oil wet reservoirs give the least oil recovery and the best recovery 
appears to be the intermediate wet reservoirs. These findings are consistent with the results of the present work. Sharma and Filoco (2005) also suggested that low-salinity brine changes the wetting properties of the rock surface from water-wet to mixed-wet and thereby increase the recovery.

Figure 10 shows that there is hardly any change in the contact angle between the original SW brine and the 5,000$\mathrm{ppm}$ solution of the SW brine. This observation may explain the results presented earlier in Fig. 5 where

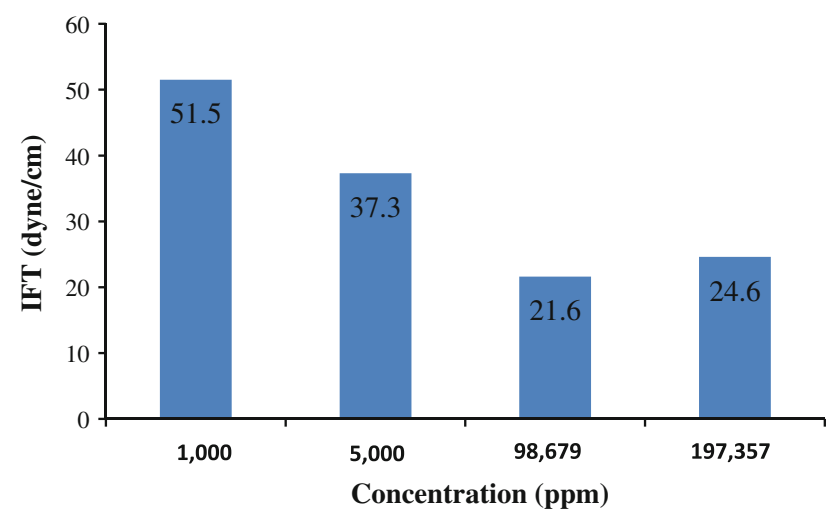

Fig. 13 Results of IFT measurements for UER brines and its diluted samples

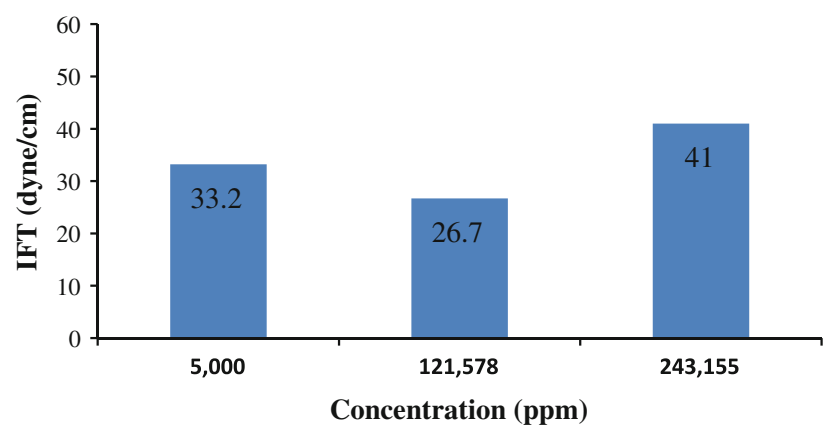

Fig. 14 Results of IFT measurements for SIM brines and its diluted samples

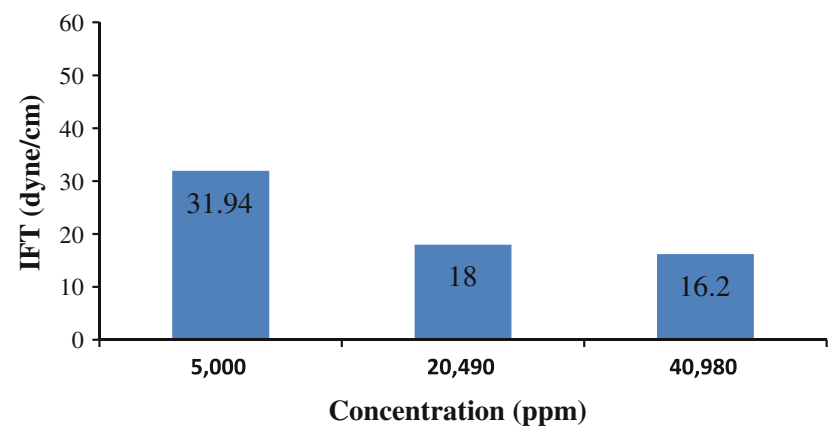

Fig. 15 Results of IFT measurements for SW brines and its diluted samples flooding with low-salinity flooding SW has no effect on the oil recovery. Also shown in Fig. 5 that the oil recovery performances in the three runs including distilled water are comparable.

In order to investigate the effect of changing the ionic composition on wettability, eight brines with different concentration of $\mathrm{Ca}^{2+}$ and $\mathrm{SO}_{4}{ }^{2-}$ were used. The $\mathrm{Ca}^{2+}$ concentration ranges from 332 to $1992 \mathrm{ppm}$. The $\mathrm{SO}_{4}{ }^{2-}$ concentration ranges from 11.7 to $70.2 \mathrm{ppm}$. Figures 11 and 12 show the results of the contact angle measurements for different $\mathrm{SO}_{4}{ }^{2-}$ and $\mathrm{Ca}^{2+}$ concentrations, respectively.

Figure 11 shows that the highest angle of contact was observed at $46.8 \mathrm{ppm}$ concentration of $\mathrm{SO}_{4}{ }^{2-}$. This

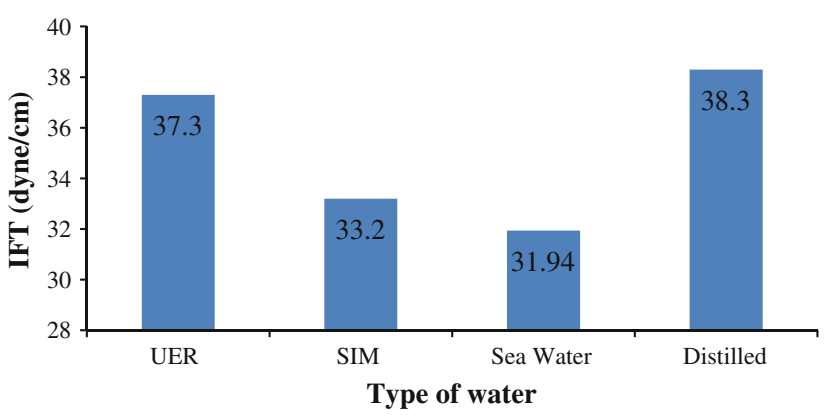

Fig. 16 Results of IFT measurements for UER, SIM and SW brines at 5,000 ppm dilution

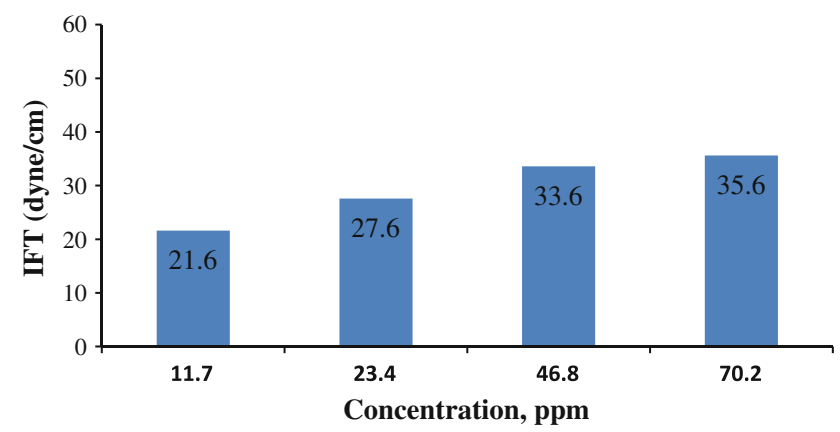

Fig. 17 Results of IFT measurements for different $\mathrm{SO}_{4}{ }^{2-}$ concentrations

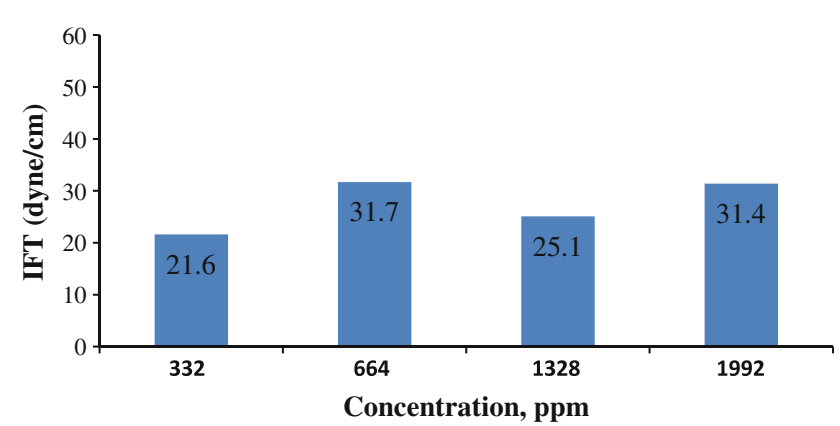

Fig. 18 Results of IFT measurements for different $\mathrm{Ca}^{2+}$ concentrations 
Fig. 19 Results of $\mathrm{pH}$ measurements for different brines

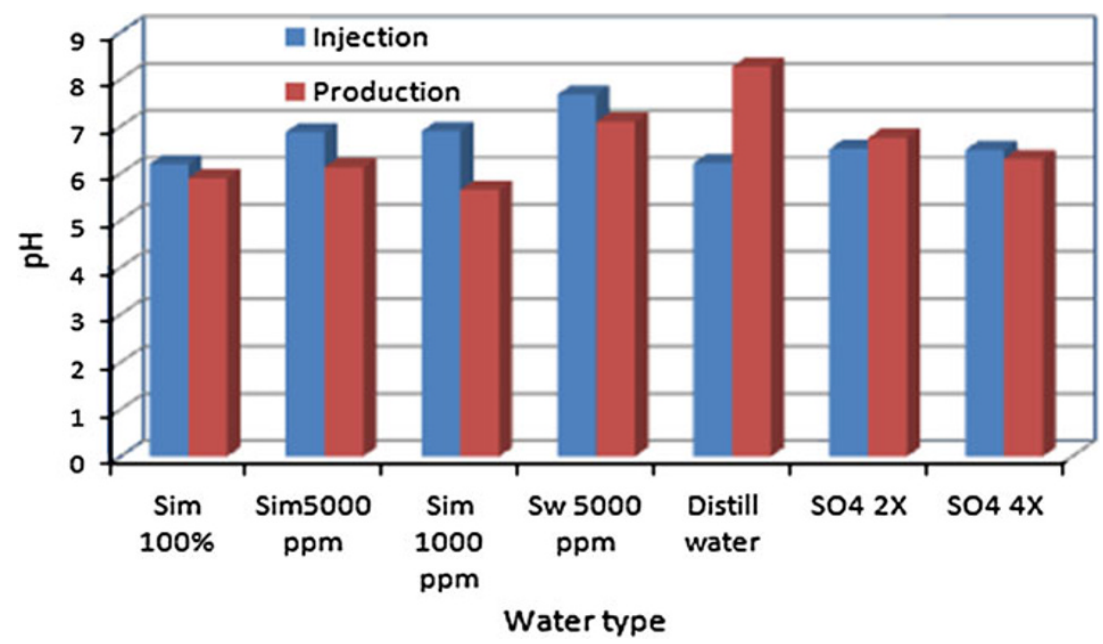

No fluctuations were observed in the IFT measurements

observation could explain the results of Fig. 6 as the 46.8ppm concentration of $\mathrm{SO}_{4}{ }^{2-}$ yields the highest recovery and confirms the results of Agbalaka et al. (2008). These authors concluded that the best recovery appears to be achieved in the intermediate wet reservoirs. Zekri et al. (2011) investigated the effect of EOR techniques on wettability and oil recovery of carbonate and sandstone formation. They concluded that increasing the sulfate concentration in the injection brine changed the wettability of the chalky and microcrystalline limestone used in their experiments into more water-wet.

IFT measurements

Interfacial tension measurements (IFT) were conducted with the interfacial tensiometer using $\mathrm{Bu}$ Hasa crude oil and different brines to assess the effect of IFT on the mechanism of low-salinity flooding. All measurements were carried out at room temperature of $25{ }^{\circ} \mathrm{C}$ and the results of these tests are illustrated in Figs. 13, 14, 15, 16, 17 , and 18 .

No systematic trend on the effect of $\mathrm{Ca}^{2+}$ on IFT measurements was observed in this work and this may explain the high oil recovery with the lowest concentration of $\mathrm{Ca}^{2+}$ that exhibited lowest value of IFT. The results also indicate that there is an optimum salinity for different tested brines but the observed optimum salinity does not correlate with the optimum oil recovery by low-salinity flooding. Therefore, interfacial tension may not be responsible for the increase in oil recovery due to the injection of low-salinity water. This observation contradicts the results of Okasha and Al-Shiwaish (2008) who investigated the effect of brine salinity on interfacial tension in Arab-D carbonate reservoir in Saudi Arabia. He concluded that the reduction of IFT with brine dilution reflects the potential implication of low-salinity flooding in improving oil recovery. and excellent repeatability of selected measurements was noted.

$\mathrm{pH}$ measurements

Some studies have shown a rise in $\mathrm{pH}$ during low-salinity flooding experiments. This rise in $\mathrm{pH}$ is due to two reactions: carbonate dissolution and cation exchange. The dissolution of carbonate (i.e., calcite and/or dolomite) results in an excess of $\mathrm{OH}-$ and cation exchange occurs between clay minerals and the invading water. The dissolution reactions are relatively slow and dependent on the amount of carbonate material present in the rock (Lager et al. 2006). Conflicting evidence throws doubt on this mechanism being the cause of the low-salinity flooding effect. The results obtained from the core flooding experiments and $\mathrm{pH}$ measurements of this study indicate no correlation between the $\mathrm{pH}$ variation and improved oil through low-salinity flooding as shown in Fig. 19. Therefore, high $\mathrm{pH}$ may not be responsible for the increase in oil recovery with low-salinity waterflooding.

\section{Conclusions}

Based on the results of the experimental work conducted in this study the following conclusions may be drawn:

1. Low-salinity flooding seems to have good potentials in Bu Hasa field.

2. Contact angle measurements indicate that lowering the solution salinity could shift the wettability of the system towards intermediate levels and this effect appears to be responsible for the improved oil recovery.

3. Increasing the $\mathrm{Ca}^{2+}$ concentration in the injected brine resulted in decreased ultimate oil recoveries. 
4. Increasing the $\mathrm{SO}_{4}{ }^{2-}$ concentration in the injected brine tends to change the wettability to more intermediate levels and resulted in improved ultimate oil recoveries. However, there is an optimum $\mathrm{SO}_{4}{ }^{2-}$ concentration of $46.8 \mathrm{ppm}$ in the 5,000 ppm UER which resulted in highest oil recovery. It is believed that this optimum concentration of $\mathrm{SO}_{4}{ }^{2-}$ in the flooding tests is responsible for shifting the system's wettability to intermediate water-wet.

5. The IFT of the oil-brine system may not have a direct effect on low-salinity flooding overall performance.

Acknowledgments The authors would like to express their appreciation for the financial support received from ADNOC and ADCO operating companies. Acknowledgment is extended to ADNOC R\&D OSC EOGR Technical Committee for their technical support. Also we would like to acknowledge the faculty of Engineering and Research Affairs at UAEU for their continuous support and encouragements.

Open Access This article is distributed under the terms of the Creative Commons Attribution License which permits any use, distribution, and reproduction in any medium, provided the original author(s) and the source are credited.

\section{References}

Agbalaka C, Abhijit Y. Dandekar, Shirish L. Patil, Khataniar S, Hemsath JR (2008) The effect of wettability on oil recovery: a review, paper SPE 114496 presented at SPE Asia Pacific oil and gas conference and exhibition, Perth, Australia, 20-22 October 2008

Bagci S, Kok MV, Turksoy U (2001) Effect of brine composition on oil recovery by waterflooding. Pet Sci Technol 19(3-4):359-372

Fjelde I (2008) Low salinity water flooding experimental experience and challenges. Force RP work shop: low salinity water flooding, the importance of salt content in injection water, Stavanger, Norway, 15 May

Høgnesen EJ, Strand S, Austad T (2005) Waterflooding of preferential oil-wet carbonates: oil recovery related to reservoir temperature and brine composition. Paper SPE 94166 presented at the SPE Europec/EAGE Annual Conference, Madrid, Spain, 13-16 June

Jadhunandan PP, Morrow NR (1995) Effect of wettability on waterflooding recovery for crude-oil/brine/rock systems. SPE reservoir engineering, 40-46 February

Lager A, Webb KJ, Black CJJ, Singleton M, Sorbie KS (2006) Low salinity oil recovery-an experimental investigation. Paper SCA2006-36 presented at the International Symposium of the Society of Core Analysts held in Trondheim, Norway, 12-16 September

Lager A, Webb KJ, Collins IR, Richmond DM (2008) LoSal ${ }^{\mathrm{TM}}$ enhanced oil recovery: evidence of enhanced oil recovery at the reservoir scale. Paper SPE 113976 presented at the 2008 SPE/ DOE improved oil recovery symposium held in Tulsa, Oklahoma, USA, 19-23 April

Ligthelm DJ et al (2009) Novel waterflooding strategy by manipulation of injection brine composition, EUROPEC/EAGE conference and exhibition. Society of Petroleum Engineers, Amsterdam, The Netherlands

Okasha TM, Al-Shiwaish A-JA (2008) Effect of Brine Salinity on Interfacial Tension in Arab-D Carbonate Reservoir, Saudi Arabia, paper SPE presented at SPE Middle East Oil and Gas Show and Conference, Bahrain, Bahrain 15-18 March 2009

$\mathrm{Pu} \mathrm{H}$, Xie X, Yin P, Morrow NR (2008) Application of coalbed methane water to oil recovery from tensleep sandstone by low salinity waterflooding, SPE/DOE symposium on improved oil recovery. Society of Petroleum Engineers, Tulsa, Oklahoma, USA

Sharma MM, Filoco PR (2005) Effect of brine salinity and crude-oil properties on oil recovery and residual saturations, SPE 65402: September 2000, 5(3):293-300

Strand S, Austad T (2008) Effect of temperature on enhanced oil recovery from mixed-wet chalk cores by spontaneous imbibition and forced displacement using seawater. Energy Fuels 22(5): $3222-3225$

Tang GQ, Morrow NR (1997) Salinity, temperature, oil composition and oil recovery by waterflooding SPE 36680. 12(4):269-276

Tang G, Morrow NR (1999a) Oil recovery by waterflooding and imbibition-invading brine cation valency and salinity. Paper SCA9911

Tang GQ, Morrow NR (1999b) Influence of brine composition and fines migration on crude oil/brine/rock interactions and oil recovery. J Pet Sci Eng 24:99-111

Vledder P, Carrera Fonseca J, Gonzalez I, Ligthelm D (2010) Low salinity water flooding: proof of wettability alteration on a field wide scale. Paper SPE 129564 presented at SPE improved oil recovery symposium, Tulsa, Oklahoma, USA, 24-28 April 2010

Webb KJ, Black CJJ, Al-Ajell H (2003) Low salinity oil recovery log-inject-log, SPE 81460 presented at middle east oil show, Bahrain, 9-12 June 2003

Webb KJ, Black CJJ, Tjetland G (2005) A laboratory studyinvestigating methods for improving oil recovery in carbonates. Paper IPTC 10506 presented at the International Petroleum Technology Conference, Doha, Qatar, 21-23 November

Yildiz HO, Morrow NR (1996) Effect of brine composition on recovery of Moutray crude oil by waterflooding. J Petrol Sci Eng 14:159-168

Zekri AY, Nasr M, Zaid A (2011) Effect of $L o S a l^{T M}$ on the wettability and oil recovery of carbonate and sandstone formation. Paper SPE 14131 presented at the international petroleum technology conference, Bangkok, Thailand, 15-17 November 2011

Zhang Y, Morrow NR (2006) Comparison of secondary and tertiary recovery with change in injection brine composition for crude oil/sandstone combinations, SPE 99757

Zhang Y, Xie X, Morrow NR (2007) Waterflood performance by injection of brine with different salinity for reservoir cores. Paper SPE 109849 presented at the 2007 SPE annual technical conference and exhibition in Anaheim, California, USA, 11-14 November 